\title{
METHOD FOR INTRODUCING ZEOLITES AND MCM-41 INTO POLYPROPYLENE MELT-BLOWN NONWOVENS
}

\author{
Agnieszka Brochocka1', Aleksandra Zagawa', Rafał Panek², Jarosław Madej², Wojciech Franus²
}

${ }^{1}$ Central Institute for Labor Protection, National Research Institute, Department of Personal Protective Equipment, Warsaw, Poland

${ }^{2}$ Lublin University of Technology, Faculty of Civil Engineering and Architecture, Department of Geotechnical Engineering, Lublin, Poland Corresponding author: e-mail: agbro@ciop.lodz.pl (A. Brochocka)

\section{Abstract:}

In this work, a method for introducing zeolites and mesoporous siliceous materials into the melt-blown process for the production of polypropylene nonwovens was developed and the functional materials obtained were tested. Both types of additives were introduced in the melt-blown technology using a device placed in the duct of the die assembly. Nine types of polypropylene melt-blown nonwovens were made with different types of zeolites (clinoptilolite, Na-X, Na-A, Na-P1, sodalite, Na-P1 with hexadecyl trimethylammonium bromide (HDTMA), ZeoEco 20, and BioZeo R.01) or mesoporous silica material (Mobil Composition of Matter No. 41 , abbreviated as MCM-41). The nonwovens were studied in terms of protective and functional parameters: sodium chloride and paraffin oil mist aerosol penetration, airflow resistance, and sorption capacity for toluene, ammonia, acetone, and cyclohexane, in accordance with the requirements of the European standards concerning respiratory protective equipment. The tests showed that zeolites and MCM-41 can be successfully incorporated within the structure of elementary polymer fibers using an environmentally friendly "dry" melt-blown technology with nonwovens modified so as to impart multiple functionalities in one integrated technological process. The developed method of introducing the studied materials to polypropylene melt-blown nonwovens led to the production of new multipurpose materials with good protective and functional properties. The best polypropylene nonwovens were produced with the addition of $250 \mathrm{~g} / \mathrm{m}^{2}$ of MCM-41 or Na-P1 zeolite modified with HDTMA.

\section{Keywords:}

melt-blown process, zeolites, polypropylene nonwoven, mesoporous silica, sorption capacity of organic vapors

\section{Introduction}

The 21 st century has brought about numerous threats arising from technological advances. One of the major problems is air pollution caused by intensive industrial development (especially in the food, chemical, paper, tanning, oil, and steel sectors), increased traffic, as well as the concentration of the sources of pollution in urban areas. The rapid growth of cities and the related municipal infrastructure (sewage treatment plants, solid waste transfer stations, composting facilities, and waste dumps), as well as the growing use of renewable energy sources, leads to greater emissions of odors, with adverse environmental effects [1]. By definition, odors are organic and inorganic volatile chemical compounds with low olfactory thresholds, which are detected by stimulating the olfactory epithelial cells, leading to pleasant or unpleasant sensations. Some of those substances may lead to psychological discomfort and - in extreme cases -symptoms of illness, such as headache, vomiting, diarrhea, respiratory and eye irritation, as well as depression [2, 3].

While the available literature discusses the main sources of odor emissions and evaluation thereof, there is scarcity of information about the application of respiratory protective devices, such as air-purifying respirators, to prevent the inhalation of such compounds. If the maximum allowable concentrations of harmful substances are exceeded, it is necessary to use absorbent or combined absorbent-and- filtering devices, including the aforementioned purifying respirators with anti-malodorous effects. In addition to a system of polypropylene (PP) melt-blown nonwoven with different morphological structures, such respirators are also equipped with one or more nonwoven layers containing carbon absorbents to reduce the amount of chemical substances entering the breathing zone. However, the protective effects of such respirators are extremely short-lived, amounting to several seconds, depending on the type and concentration of modifier, breathing cycle characteristics, relative air humidity, and carbon geometry in the polymer fibers.

Recently, a substantial body of research has shown interesting possibilities of using nonwoven structures in advanced applications in a variety of sectors, including the construction industry, medicine, transportation, textiles, the automotive industry, and so on [4-6]. Such nonwovens may differ in terms of quantitative and qualitative composition, morphological structure, physical and chemical properties of the incorporated modifiers, hydrophilicity and hydrophobicity, as well as structural modification technologies [7-16].

Over the past years, increased sensitivity to micro- and nanometric particles has induced greater user expectations concerning enhanced filtering properties of nonwovens. Highquality PP melt-blown nonwovens are needed, for instance, in sectors using the so-called clean technologies [17, 18]. The 
requirements concerning the design and evaluation of such products become increasingly stricter. The melt-blown process is the most suitable technique for the production of modified filtering nonwovens. Melt-blown technology was chosen as the structure of nonwovens can be effectively adjusted in terms of porosity and area density. Another advantage is that the manufacturing equipment is more compact than that used in other nonwoven fabrication methods. It should be noted that the melt-blown process is very flexible and easily yields itself to different modifications. Despite requiring a high-energy input due to the high process temperature and the considerable use of hot air, melt-blowing is nevertheless preferable for environmental reasons as a so-called "dry technology".

Activated carbons have long been used in absorptive respiratory protective devices to remove a variety of vapors and gases from the air. Those carbons are characterized by extremely large specific areas and a high density of pores with various shapes and sizes. This structure facilitates the contact of chemical substances with the active sites located on the adsorbent surface. The size and shape of the pores ensures appropriate transport of the adsorbed particles. Importantly, the larger the specific area, the greater is the fraction of fine pores. Thus, the amount of adsorbed substance depends on the specific area of the adsorbent and its pore size distribution [19-21].

Furthermore, in recent years, increased attention has been given to natural and synthetic minerals known as zeolites, which exhibit molecular sieving, ion exchange, and sorption properties. Natural zeolites can be found in a variety of geological environments, while synthetic ones may be obtained by conversion of fly ash in strongly alkaline aqueous solutions [22].

Zeolites are a group of tectoaluminosilicates with complex and diverse crystalline structures containing voids known as cages and channels, which may enclose both individual atoms and chemical molecules. This morphological structure gives rise to a number of physical and chemical properties that are extremely beneficial in industrial applications, such as wastewater treatment; indeed, modified zeolites may be used to treat ground and surface water, municipal and industrial liquid waste, as well as petroleum pollution. Due to their hydrophobic properties, zeolites have an affinity for organic compounds [23, 24], while as a result of their hydrophilicity, they effectively remove moisture from gases [25, 26]. Previous works [27, 28] give an overview of the latest research concerning synthetic zeolites and their variants modified with organic compounds, which have been used to remove petroleum products (including oils and volatiles) from the air, water, and ground. According to data from literature, highly mesoporous minerals are recommended for removing land oil spills. The most promising results were found for diatomite, sepiolite, and Na-P1 zeolite (synthesized from fly ash). The latest research has shown that $Y$ zeolites $(\mathrm{Na}-\mathrm{Y}, \mathrm{Si} / \mathrm{Al}=2.5)$ are good materials for the production of stable, selective, and economical sensors for ammonia vapor $\left(\mathrm{NH}_{3}\right)$. Ammonia sorption has been studied in ion-exchanged $\mathrm{Y}$ zeolites containing alkali metals (lithium and sodium - Li-Y and $\mathrm{Na}-\mathrm{Y}$, respectively), rare earth metals (lanthanum - La$\mathrm{Y}$ ), and noble metals (silver and palladium - Ag-Y and Pd-Y, respectively). Interactions between modified zeolites and ammonia are effectively improved by their ionic conductivity. The excellent selectivity of $\mathrm{Ag}-\mathrm{Y}$ and $\mathrm{Na}-\mathrm{Y}$ proves that they are good materials for ammonia vapor detectors [29]. Furthermore, different parameters of a natural zeolite (clinoptilolite) have been studied in terms of xylene vapor sorption. Clinoptilolite has been found to be a promising sorbent of xylene vapor in the concentration range from 100 to $300 \mathrm{ppm}$. The absorption rate increases with xylene concentration, while the breakthrough time becomes shorter [30]. Gregis et al. [31] reported that the best carbon and zeolite sorbents for trace amounts of toluene vapor are W5 activated carbon and $\mathrm{Na}-\mathrm{Y}$ zeolite, respectively, due to their large specific areas and considerable microporosity.

Numerous publications deal with modifications of the morphological structure and chemical composition of zeolites with a view to obtaining catalysts and sorbents with superior microporosity, surface topology, and properties well suited for a variety of commercial processes. Most reports focus on the effectiveness of zeolite synthesis in conversion reactions, as a function of substrate concentration, reaction time, and temperature.

The particularly innovative aspects of the presented project involve the direct addition of modifiers during the melt-blown production process with a view to obtaining multifunctional polymer materials. Currently, in the European market, there is no melt-blown zeolite or mesoporous silica material composite that would exhibit both high filtration effectiveness at low airflow resistance and a good, long-term capacity for adsorbing volatiles, such as toluene, acetone, ammonia, hydrogen sulfide, and xylene. The development of respiratory protective devices using filtration composites containing zeolites and/or Mobil Composition of Matter No. 41 (MCM-41) may reduce the hazards arising from working in environments containing noisome odoriferous, malodorous, or otherwise foul-smelling substances.

\section{Materials and methods}

Melt-blown nonwovens were produced from isotactic PP granulate Borealis HL 508J, supplied by Nexeo Solutions Poland Sp. z o.o., whose characteristics are given in Table 1.

The following types of materials were used as additives: ZeoEco 20 zeolite (from ZeoCem, a.s., Slovakia), clinoptilolite, $\mathrm{Na}-\mathrm{X}$ zeolite, sodalite, Na-A zeolite, Na-P1 zeolite, Na-P1 zeolite modified with hexadecyl trimethylammonium bromide (HDTMA), and mesoporous silica material MCM-41 (from the Department of Geotechnical Engineering, Faculty of Civil Engineering and Architecture, Lublin University of Technology, Poland), and BioZeo R.01 zeolite (from BioDrain Sp. z o.o., Poland).

The characteristics of the studied materials are given in Table 2. 
Table 1. Characteristics of Borealis HL 508J PP

\begin{tabular}{|c|c|c|c|}
\hline Polymer type & Melting point, ${ }^{\circ} \mathbf{C}$ & Melt-flow index, $\mathbf{g} / \mathbf{1 0}$ min & ${\text { Density, } \mathbf{g} / \mathbf{c m}^{2}}^{\mathbf{2}}$ \\
\hline PP & $156-160$ & 800 & 50.3 \\
\hline
\end{tabular}

Table 2. Textural parameters of the studied modifiers

\begin{tabular}{|c|c|c|c|c|c|c|c|c|c|}
\hline Modifier type & Clinoptilolite & $\mathrm{Na}-\mathrm{X}$ & $\mathrm{Na}-\mathrm{A}$ & Na-P1 & Sodalite & $\begin{array}{l}\text { Na-P1 } \\
\text { HDTMA }\end{array}$ & MCM-41 & ZeoEco 20 & $\begin{array}{c}\text { BioZeo } \\
\text { R.01 }\end{array}$ \\
\hline $\begin{array}{l}\text { Brunauer- } \\
\text { Emmett-Teller } \\
\text { (BET) surface } \\
\text { area, } \mathrm{m}^{2} / \mathrm{g}\end{array}$ & 18.327 & 333.327 & 98.134 & 61.185 & 53.641 & 26.257 & $1,133.646$ & 32.804 & 33,303 \\
\hline $\begin{array}{c}\text { Langmuir } \\
\text { surface area, } \\
\mathrm{m}^{2} / \mathrm{g}\end{array}$ & 23.227 & 488.341 & 141.337 & 91.053 & 67.969 & 33.963 & - & - & - \\
\hline $\begin{array}{c}\text { t-Plot micropore } \\
\text { area, } \mathrm{m}^{2} / \mathrm{g}\end{array}$ & 10.65 & 189.202 & 67.667 & 9.425 & 24.914 & 3.668 & & - & - \\
\hline $\begin{array}{l}\text { Barrett-Joyner- } \\
\text { Halenda (BJH) } \\
\text { adsorption } \\
\text { cumulative } \\
\text { surface area of } \\
\text { pores between } \\
1.7000 \mathrm{~nm} \text { and } \\
300.0000 \mathrm{~nm}^{2} \text { in } \\
\text { diameter, } \mathrm{m}^{2} / \mathrm{g}\end{array}$ & 8.944 & 160.877 & 37.714 & 58.073 & 32.101 & 16.507 & - & - & - \\
\hline $\begin{array}{l}\text { BJH desorption } \\
\text { cumulative } \\
\text { surface area of } \\
\text { pores between } \\
1.7000 \mathrm{~nm} \text { and } \\
300.0000 \mathrm{~nm} \text { in } \\
\text { diameter, } \mathrm{m}^{2} / \mathrm{g}\end{array}$ & 11.181 & 159.144 & 45.606 & 65.994 & 47.057 & 28.355 & - & - & - \\
\hline $\begin{array}{l}t \text {-Plot micropore } \\
\text { volume, } \mathrm{cm}^{3} / \mathrm{g}\end{array}$ & 0.0046 & 0.0968 & 0.0342 & 0.0045 & 0.0126 & 0.001 & 0.003 & - & - \\
\hline $\begin{array}{l}\text { BJH adsorption } \\
\text { cumulative } \\
\text { volume of } \\
\text { pores between } \\
1.7000 \mathrm{~nm} \text { and } \\
300.0000 \mathrm{~nm} \text { in } \\
\text { diameter, } \mathrm{cm}^{3} / \mathrm{g}\end{array}$ & 0.0543 & 0.2629 & 0.1495 & 0.1532 & 0.2593 & 0.082 & - & - & - \\
\hline $\begin{array}{l}\text { BJH desorption } \\
\text { cumulative } \\
\text { volume of } \\
\text { pores between } \\
1.7000 \mathrm{~nm} \text { and } \\
300.0000 \mathrm{~nm} \text { in } \\
\text { diameter, } \mathrm{cm}^{3} / \mathrm{g}\end{array}$ & 0.0556 & 0.263 & 0.1532 & 0.1584 & 0.2645 & 0.085 & - & - & - \\
\hline $\begin{array}{c}\text { Adsorption } \\
\text { average pore } \\
\text { width (4 V/A by } \\
\text { BET), nm }\end{array}$ & 10.9093 & 4.0072 & 6.7776 & 9.5155 & 17.4744 & 11.837 & - & - & - \\
\hline $\begin{array}{c}\text { Desorption } \\
\text { average pore } \\
\text { width (4 V/A by } \\
\text { BET), nm }\end{array}$ & 10.0476 & 4.1944 & 7.3758 & 9.8911 & 18.3471 & 11.628 & - & - & - \\
\hline
\end{tabular}




\subsection{Production of PP melt-blown nonwovens containing zeolites or MCM-41}

In melt-blown technology, the polymer melt is attenuated by hot air jets into elementary fibers of various thicknesses and lengths, which are then electrostatically activated. The experimental stand consisted of a BX12 (Axon, Nyvang, Sweden) laboratory extruder enabling simultaneous intensive mixing, plasticizing, and feeding the processed polymer. The basic element of the device was a cylinder with a rotating screw of diameter $12 \mathrm{~mm}$ and a length-to-diameter ratio of 26 . The polymer was plasticized and homogenized in the cylinder, which was divided into two zones equipped with independent heating systems. The polymer melt was maintained at an appropriate temperature to obtain the desirable viscosity upon feeding to the plasticizing zone of the die assembly. The amount of melt produced was controlled by adjusting the rotational speed of the screw (the higher the speed was, the greater was the amount of plasticized melt produced). During the process, it was critical that the extruded polymer melt be characterized by constant weight and temperature. The target viscosity, ensuring the formation of fine fibers, was achieved by means of an appropriately designed die assembly. The role of the die assembly was to ensure that the polymer melt had the right temperature upon leaving the orifices, when it was subjected to the action of a stream of hot air, forming elementary fibers. The material feeder consisted of a hopper, whose outlet was placed in the channel of the die assembly. Materials were pushed through the channel by means of a screw running symmetrically along the central axis of the channel, down to the polymer outlet zone; the screw was powered by a variable-speed motor drive (Figure 1). Thus, the nanomaterials were mixed continuously and fed into the polymer stream in a fully controlled manner. This technical solution also reduced the screw and cylinder wear attributable to friction from the modifiers. During the presented experiments, the modifiers were fed in amounts of up to $250 \mathrm{~g} / \mathrm{m}^{2}$ of nonwoven. In addition, the fibers mixed with zeolites or MCM-41 were activated electrostatically by corona discharges in order to improve their filtration properties. The charge carriers generated by the discharges resulting from the potential difference between the electrode and counter electrode were adsorbed on the nonwoven surface under the influence of an electrostatic field. The plasma-activated fibers with additives were deposited on the collector, forming compact and porous nonwoven sheets.

The greatest advantage of the presented solution is that zeolites and MCM-41 are fed directly into the polymer melt stream, which leads to very strong binding of mineral particles to the elementary PP fibers.

Controlling the temperatures of the die assembly as well as zones 1 and 2 of the extruder, one may obtain different densities of the thermoplastic polymer melt, which is critical to fiber formation parameters. The other important factors are air temperature and an appropriate polymer-to-airflow ratio. Furthermore, control of the linear or angular speed of the collector enables adjustment of the nonwoven surface density and fiber-packing density.

The melt-blowing parameters of filtration nonwovens containing zeolites or MCM-41 are given in Table 3.

\subsection{Characteristics of the nonwovens produced}

The developed method of zeolite and MCM-41 feeding was used to produce nine nonwoven variants (three sheets with an area of $5.0 \mathrm{~m}^{2}$ per variant), which were modified by corona discharges and by the incorporation of zeolites or mesoporous silica material in the total amount of $250 \mathrm{~g} / \mathrm{m}^{2}$. The characteristics of the obtained nonwovens are presented in Table 4.

\section{$\underline{2.3 \text { Methods }}$}

The protective parameters of the modified PP melt-blown nonwovens containing zeolite particles or MCM- 41 were studied in terms of the basic filtration parameters: airflow resistance,

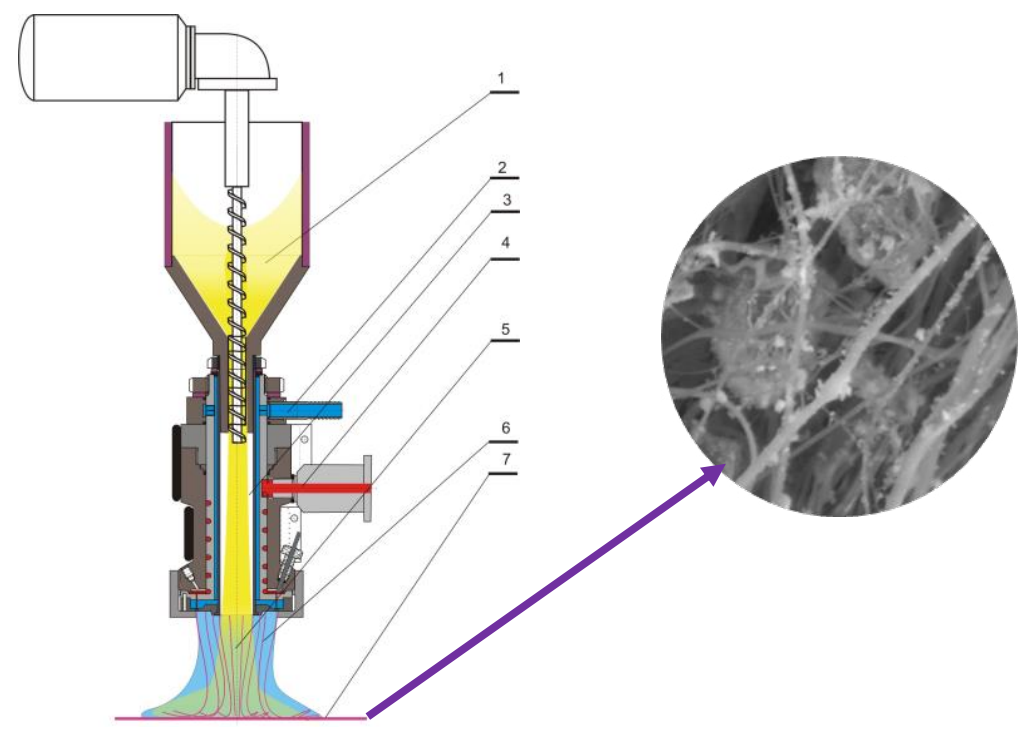

Figure 1. Device for introducing zeolites and MCM-41 into the structure of elementary fibers: 1 - zeolite or MCM-41, 2 - melt-blowing air, 3 modifier duct, 4 - polymer melt from the extruder, 5 - mixture of fibers, modifier, and air, 6 - polymer fibers, 7 - structure of modified nonwoven material 
Table 3. Melt-blowing parameters of filtration nonwovens

\begin{tabular}{c|c}
\hline Technological parameter & Value \\
\hline Extruder temperature in Zone $1, T_{1},{ }^{\circ} \mathrm{C}$ & 280.0 \\
\hline Extruder temperature in Zone $2, T_{2},{ }^{\circ} \mathrm{C}$ & 270.0 \\
\hline Air temperature, $T_{\mathrm{p}},{ }^{\circ} \mathrm{C}$ & 320.0 \\
\hline Die assembly temperature, $T_{\mathrm{d}},{ }^{\circ} \mathrm{C}$ & 314.0 \\
\hline Airflow rate, $\mathrm{m}^{3} / \mathrm{h}$ & 5.6 \\
\hline Polymer flow rate, $\mathrm{g} / \mathrm{min}$ & 29.0 \\
\hline Die-to-collector distance, $\mathrm{cm}$ & 28.0 \\
\hline
\end{tabular}

Table 4. Characteristics of melt-blown filtration nonwovens containing zeolites or MCM-41

\begin{tabular}{|c|c|c|c|c|c|}
\hline No. & Type of filtration nonwoven & Symbol & $\begin{array}{c}\text { Mean } \\
\text { surface } \\
\text { density, } \\
\text { g/m2 }\end{array}$ & $\begin{array}{c}\text { Mean fiber } \\
\text { thickness, } \\
\text { mm }\end{array}$ & $\begin{array}{c}\text { Mean nonwoven } \\
\text { thickness, } \\
\text { mm }\end{array}$ \\
\hline 1 & $\begin{array}{c}\text { PP nonwoven with electrical charge (Q) and } \\
\text { ZeoEco } 20 \text { (natural zeolite) }\end{array}$ & $P P Q+1$ & 282.70 & 0.961 & 2.96 \\
\hline 2 & $\begin{array}{c}\text { PP nonwoven with electrical charge }(\mathrm{Q}) \text { and } \\
\text { clinoptilolite (natural zeolite) }\end{array}$ & $P P Q+2$ & 434.70 & 0.890 & 2.39 \\
\hline 3 & $\begin{array}{l}\text { PP nonwoven with electrical charge }(\mathrm{Q}) \text { and } \mathrm{Na}-\mathrm{X} \\
\text { (synthetic) zeolite }\end{array}$ & $P P Q+3$ & 338.69 & 0.748 & 3.06 \\
\hline 4 & $\begin{array}{l}\text { PP nonwoven with electrical charge }(\mathrm{Q}) \text { and } \\
\text { sodalite (synthetic zeolite) }\end{array}$ & $P P Q+4$ & 307.70 & 1.040 & 3.03 \\
\hline 5 & $\begin{array}{c}\text { PP nonwoven with electrical charge }(\mathrm{Q}) \text { and } \mathrm{Na}-\mathrm{A} \\
\text { (synthetic zeolite) }\end{array}$ & $P P Q+5$ & 374.36 & 1.076 & 2.62 \\
\hline 6 & $\begin{array}{l}\text { PP nonwoven with electrical charge }(\mathrm{Q}) \text { and } \mathrm{Na}- \\
\text { P1 (synthetic zeolite) }\end{array}$ & $P P Q+6$ & 386.46 & 1.161 & 2.97 \\
\hline 7 & $\begin{array}{l}\text { PP nonwoven with electrical charge (Q) and Na- } \\
\text { P1 (synthetic zeolite modified with HDTMA) }\end{array}$ & $\mathrm{PPQ}+7$ & 507.01 & 0.870 & 2.99 \\
\hline 8 & $\begin{array}{l}\text { PP nonwoven with electrical charge }(Q) \text { and } \\
\text { MCM-41 (mesoporous silica material) }\end{array}$ & $P P Q+8$ & 146.08 & 1.107 & 2.99 \\
\hline 9 & $\begin{array}{c}\text { PP nonwoven with electrical charge }(\mathrm{Q}) \text { and } \\
\text { BioZeo R.01 (natural zeolite) }\end{array}$ & $P P Q+9$ & 507.01 & 0.903 & 3.06 \\
\hline $0^{*}$ & PP nonwoven with electrical charge (Q) & $P P Q$ & 97.00 & 1.190 & 2.35 \\
\hline
\end{tabular}

Note: ${ }^{*} 0=$ reference sample without zeolite.

penetration of solid aerosols (sodium chloride), liquid aerosols (paraffin oil mist), sorption capacity, pursuant to the following European standards: EN 13274-3:2001, EN 13274-7:2008, EN 14387:2004+AC:2004 and EN 149:2001+A1:2009 [32-35].

\subsubsection{Penetration by sodium chloride and paraffin oil mist aerosols}

Sodium chloride and paraffin oil mist aerosol penetration coefficients were determined pursuant to the standards EN
149:2001+A1:2009 and EN 13274-7:2008 concerning the testing methodology and requirements for respiratory protective devices [35, 33]. This coefficient expresses the ratio of aerosol concentrations upstream and downstream of the sample. The mass median diameter of sodium chloride particles was $0.6 \mathrm{~mm}$. The distribution of particle sizes for oil mist was lognormal, with a median Stokes diameter of $0.4 \mathrm{~mm}$. The test period corresponded to initial filtration (3 $\mathrm{min}$ ). 


\subsubsection{Airflow resistance}

Airflow resistance testing was conducted according to the European standards EN 149:2001+A1:2009 and EN 132743:2008 specifying the testing methodology and requirements for respiratory protective devices $[35,32]$. Measurement involved passing air through the filtering material at a constant airflow rate and with a negative pressure differential downstream of the material with respect to atmospheric pressure. The tests were conducted at an airflow rate of $95 \mathrm{~L} / \mathrm{min}$ corresponding to the minute respiratory volume during light and strenuous work. Pressure values were read from a CMR-10A digital differential micromanometer.

\subsubsection{Test of sorption capacity}

Sorption capacity for volatile chemicals was tested according to the European standard EN 14387: 2004+AC:2004 specifying the testing methodology and requirements for respiratory protective devices [34]. Gas detectors (analyzers) enabled measurement of the concentrations of test gases upstream and downstream of the sample in a pneumatic holder. Aerosols were generated using an evaporator in which the test substances were exposed to compressed air. Mass flow controllers were used to obtain the desired concentration of the test substance (the maximum permissible deviation of gas concentration was $\pm 5 \mathrm{ppm}$ ) at a relative humidity of $(70 \pm 5) \%$ and a temperature of $(21 \pm 1)^{\circ} \mathrm{C}$ [34]. The sorption capacity of the filtration media containing zeolites was measured for four different test substances: toluene, acetone, cyclohexane, and ammonia. Currently, reaction tests for volatiles are conducted using cyclohexane, which is not a malodorous substance with olfactory detection thresholds. The test substances were selected based on the literature data concerning odoriferous substances that are widespread at waste dumps, municipal sewage treatment plants, the oil industry, animal farms, and biomass processing $[3,5]$. The applied concentrations of toluene (50 ppm), acetone (235 ppm), cyclohexane (81 ppm), and ammonia (18.7 ppm) corresponded to the highest permissible concentrations pursuant to the regulation of the Ministry of Labor and Social Policy as of June 06, 2014 [36]. Tests were conducted at a volumetric flow rate of $30 \mathrm{~L} / \mathrm{min}$. The characteristics of the test substances are given in Table 5.

\section{Results and discussion}

\section{1. $\mathrm{NaCl}$ and paraffin oil mist aerosol penetration testing}

The mean $\mathrm{NaCl}$ aerosol penetration results for filtration nonwovens containing zeolites or MCM-41 modifiers are given in Table 6, while relative changes in those results are presented graphically in Figure 2. In turn, the mean results for paraffin oil mist aerosol penetration are given in Table 7 , with relative changes shown in Figure 3.

In four cases, the incorporation of the studied modifiers in the structure of elementary fibers adversely affected the $\mathrm{NaCl}$ aerosol filtration properties of the obtained nonwovens as compared to the reference sample. The penetration coefficients

Table 5. Properties of the test substances

\begin{tabular}{|c|c|c|c|}
\hline Substance type & Chemical Abstracts Service No. & Density, $\mathbf{g} / \mathbf{c m} 3$ & Molar mass, g/mol \\
\hline Toluene & $108-88-3$ & 0.87 & 92.14 \\
\hline Acetone & $67-64-1$ & 0.78 & 58.08 \\
\hline Cyclohexane & $110-82-7$ & 0.78 & 84.16 \\
\hline Ammonia & $7664-41-7$ & 0.0073 & 17.031 \\
\hline
\end{tabular}

Table 6. Mean $\mathrm{NaCl}$ aerosol penetration through melt-blown filtration nonwovens containing zeolites or MCM- 41 (descriptive statistics)

\begin{tabular}{|c|c|c|c|c|c|c|}
\hline No. & Symbol & Mean NaCl penetration, \% & Standard deviation & Median & Maximum, \% & Minimum, \% \\
\hline 1 & $\mathrm{PPQ}+1$ & 0.369 & 0.169 & 0.296 & 0.677 & 0.143 \\
\hline 2 & $\mathrm{PPQ}+2$ & 3.973 & 1.346 & 3.330 & 6.462 & 2.699 \\
\hline 3 & $\mathrm{PPQ}+3$ & 3.209 & 0.657 & 3.188 & 4.338 & 2.339 \\
\hline 4 & $\mathrm{PPQ}+4$ & 1.414 & 0.489 & 1.157 & 2.253 & 0.980 \\
\hline 5 & $\mathrm{PPQ}+5$ & 3.420 & 0.570 & 3.402 & 4.331 & 2.564 \\
\hline 6 & $\mathrm{PPQ}+6$ & 0.242 & 0.092 & 0.228 & 0.435 & 0.123 \\
\hline 7 & $\mathrm{PPQ}+7$ & 0.300 & 0.059 & 0.312 & 0.371 & 0.224 \\
\hline 8 & $\mathrm{PPQ}+8$ & 0.145 & 0.087 & 0.132 & 0.300 & 0.048 \\
\hline 9 & $\mathrm{PPQ}+9$ & 0.284 & 0.058 & 0.303 & 0.363 & 0.176 \\
\hline $0^{*}$ & $\mathrm{PPQ}$ & 0.677 & 0.070 & 0.674 & 0.768 & 0.571 \\
\hline
\end{tabular}

Note: *0=reference sample without modifiers. 
for the nonwovens containing clinoptilolite, $\mathrm{Na}-\mathrm{X}$, sodalite, and Na-A ranged from $1.41 \%$ to $3.97 \%$ as compared to $0.677 \%$ for the nonwoven without a modifier, which translates into a deterioration of $\mathrm{NaCl}$ aerosol filtration by $108.86 \%$ to $486.85 \%$. This indicates that some components of the morphological structure of zeolites probably neutralized the electrostatic charges in PP nonwovens.

In the case of paraffin oil mist penetration (the so-called "worst case scenario"), three of the produced PP filtration nonwovens containing zeolites exhibited a lower penetration coefficient than the reference sample without a sorbent, similarly to $\mathrm{NaCl}$ penetration. The penetration coefficient ranged from $3.68 \%$ to $5.54 \%$ for nonwovens with clinoptilolite, $\mathrm{Na}-\mathrm{X}$, and $\mathrm{Na}-\mathrm{A}$, which is significantly more than the $1.94 \%$ obtained for the reference sample (by $89.69 \%$ to $185.57 \%$, respectively). This suggests that some of the zeolites used probably neutralized the electrostatic charges present in PP nonwovens.

\subsection{Airflow resistance}

Airflow resistance test results for filtration nonwovens containing zeolites or MCM-41 are given in Table 8, with relative changes in this parameter being presented in Figure 4.

Airflow resistance did not increase for two PP melt-blown nonwovens containing modifiers, namely, for those with $\mathrm{Na}-\mathrm{X}$ and Na-A zeolites (247 $\mathrm{Pa}$ and $246 \mathrm{~Pa}$, respectively, as compared to the $286 \mathrm{~Pa}$ for the $\mathrm{PPQ}$ reference sample). In the case of the nonwoven containing clinoptilolite, airflow resistance

Table 7. Mean paraffin oil mist aerosol penetration through melt-blown filtration nonwovens containing zeolites or MCM-41 (descriptive statistics)

\begin{tabular}{|c|c|c|c|c|c|c|}
\hline No. & Symbol & $\begin{array}{c}\text { Mean penetration by paraffin oil mist } \\
\text { aerosol, \% }\end{array}$ & Standard deviation & Median & $\begin{array}{c}\text { Maximum, } \\
\%\end{array}$ & $\begin{array}{c}\text { Minimum, } \\
\%\end{array}$ \\
\hline 1 & $\mathrm{PPQ}+1$ & 0.26 & 0.093 & 0.23 & 0.37 & 0.15 \\
\hline 2 & $\mathrm{PPQ}+2$ & 3.68 & 0.711 & 3.55 & 5.10 & 2.90 \\
\hline 3 & $\mathrm{PPQ}+3$ & 5.54 & 2.220 & 5.30 & 11.0 & 3.10 \\
\hline 4 & $\mathrm{PPQ}+4$ & 1.42 & 0.509 & 1.25 & 2.50 & 0.80 \\
\hline 5 & $\mathrm{PPQ}+5$ & 4.59 & 0.722 & 4.40 & 5.90 & 3.90 \\
\hline 6 & $\mathrm{PPQ}+6$ & 0.21 & 0.054 & 0.22 & 0.28 & 0.12 \\
\hline 7 & $\mathrm{PPQ}+7$ & 0.34 & 0.062 & 0.32 & 0.49 & 0.28 \\
\hline 8 & $\mathrm{PPQ}+8$ & 0.35 & 0.038 & 0.34 & 0.40 & 0.30 \\
\hline 9 & $\mathrm{PPQ}+9$ & 0.40 & 0.077 & 0.39 & 0.57 & 0.29 \\
\hline $0^{*}$ & $\mathrm{PPQ}$ & 1.94 & 0.113 & 2.00 & 2.10 & 1.80 \\
\hline
\end{tabular}

Note: ${ }^{*} 0=$ reference sample without modifiers.

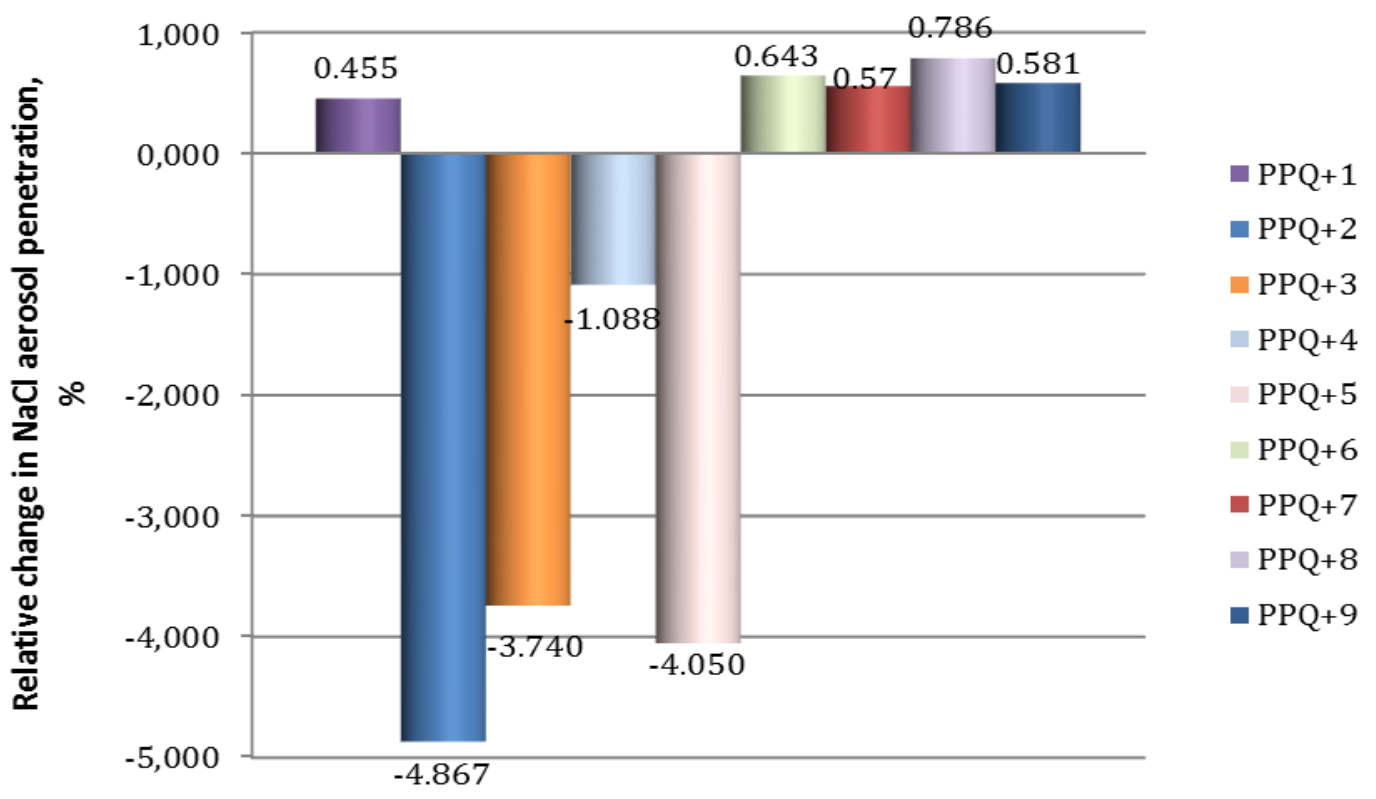

Figure 2. Relative changes in $\mathrm{NaCl}$ aerosol penetration through melt-blown filtration nonwovens containing zeolites or MCM-41 


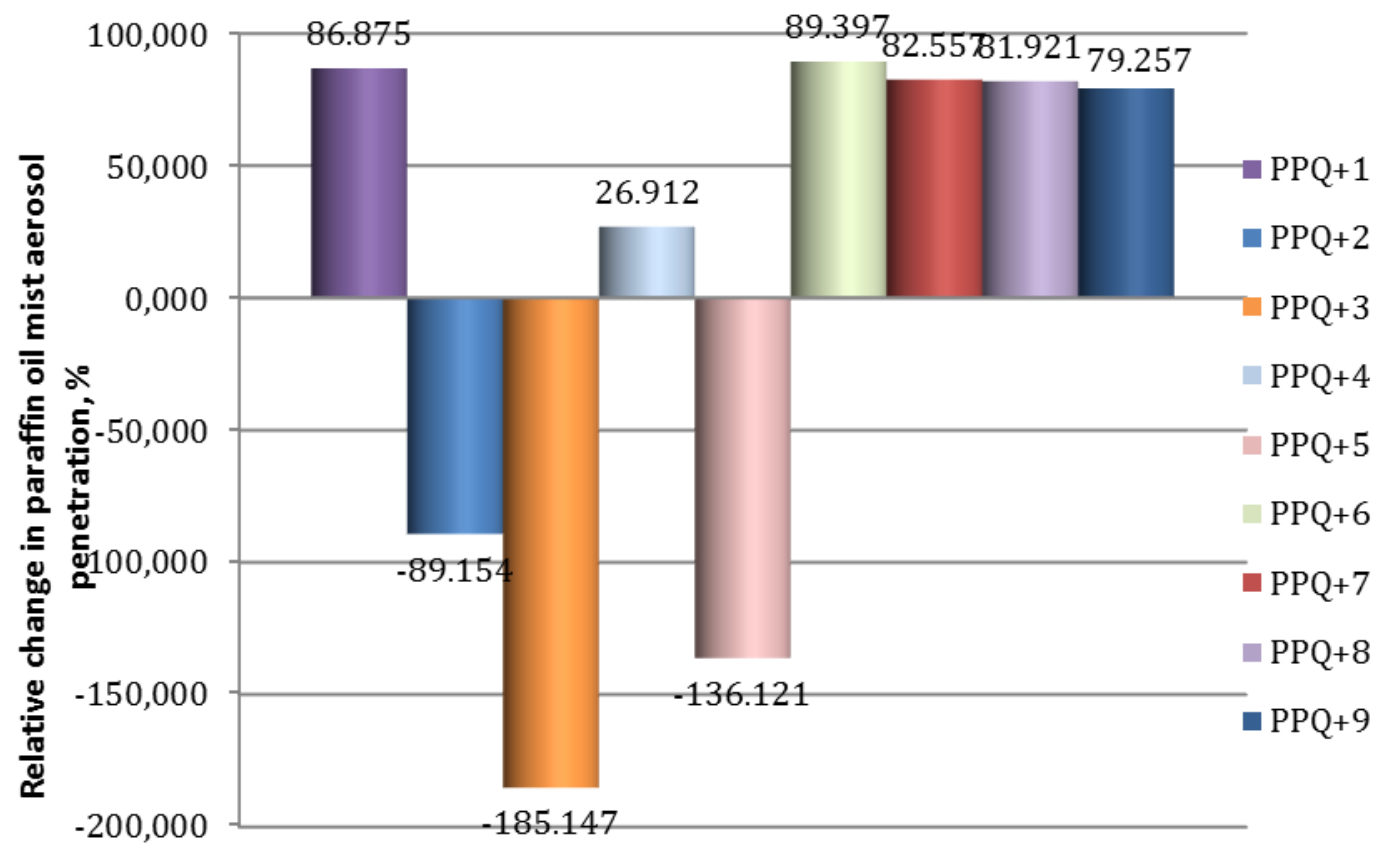

Figure 3. Relative changes in paraffin oil mist aerosol penetration through melt-blown filtration nonwovens containing zeolites or MCM-41

Table 8. Mean airflow resistance for melt-blown filtration nonwovens containing zeolites and MCM-41 (descriptive statistics)

\begin{tabular}{|c|c|c|c|c|c|c|}
\hline No. & Symbol & Mean airflow resistance, Pa & Standard deviation & Median & Maximum, $\%$ & Minimum, $\%$ \\
\hline 1 & $\mathrm{PPQ}+1$ & 918.00 & 88.139 & 919.00 & $1,097.00$ & 809.00 \\
\hline 2 & $\mathrm{PPQ}+2$ & 308.00 & 26.796 & 306.00 & 353.00 & 271.00 \\
\hline 3 & $\mathrm{PPQ}+3$ & 247.00 & 28.587 & 250.00 & 278.00 & 186.00 \\
\hline 4 & $\mathrm{PPQ}+4$ & 539.00 & 130.469 & 570.00 & 718.00 & 348.00 \\
\hline 5 & $\mathrm{PPQ}+5$ & 246.00 & 35.971 & 233.00 & 298,00 & 210.00 \\
\hline 6 & $\mathrm{PPQ}+6$ & $1,299.00$ & 80.595 & $1,283.00$ & $1,424.00$ & $1,186.00$ \\
\hline 7 & $\mathrm{PPQ}+7$ & 708.00 & 58.480 & 688.00 & 818.00 & 626.00 \\
\hline 8 & $\mathrm{PPQ}+8$ & 511.00 & 21.124 & 509.00 & 547.00 & 487.00 \\
\hline 9 & $\mathrm{PPQ}+9$ & 641.00 & 39.002 & 634.00 & 697.00 & 578.00 \\
\hline $0^{*}$ & $\mathrm{PPQ}$ & 286.00 & 10.610 & 282.00 & 307.00 & 274.00 \\
\hline
\end{tabular}

Note: ${ }^{*} 0=$ reference sample without modifiers.

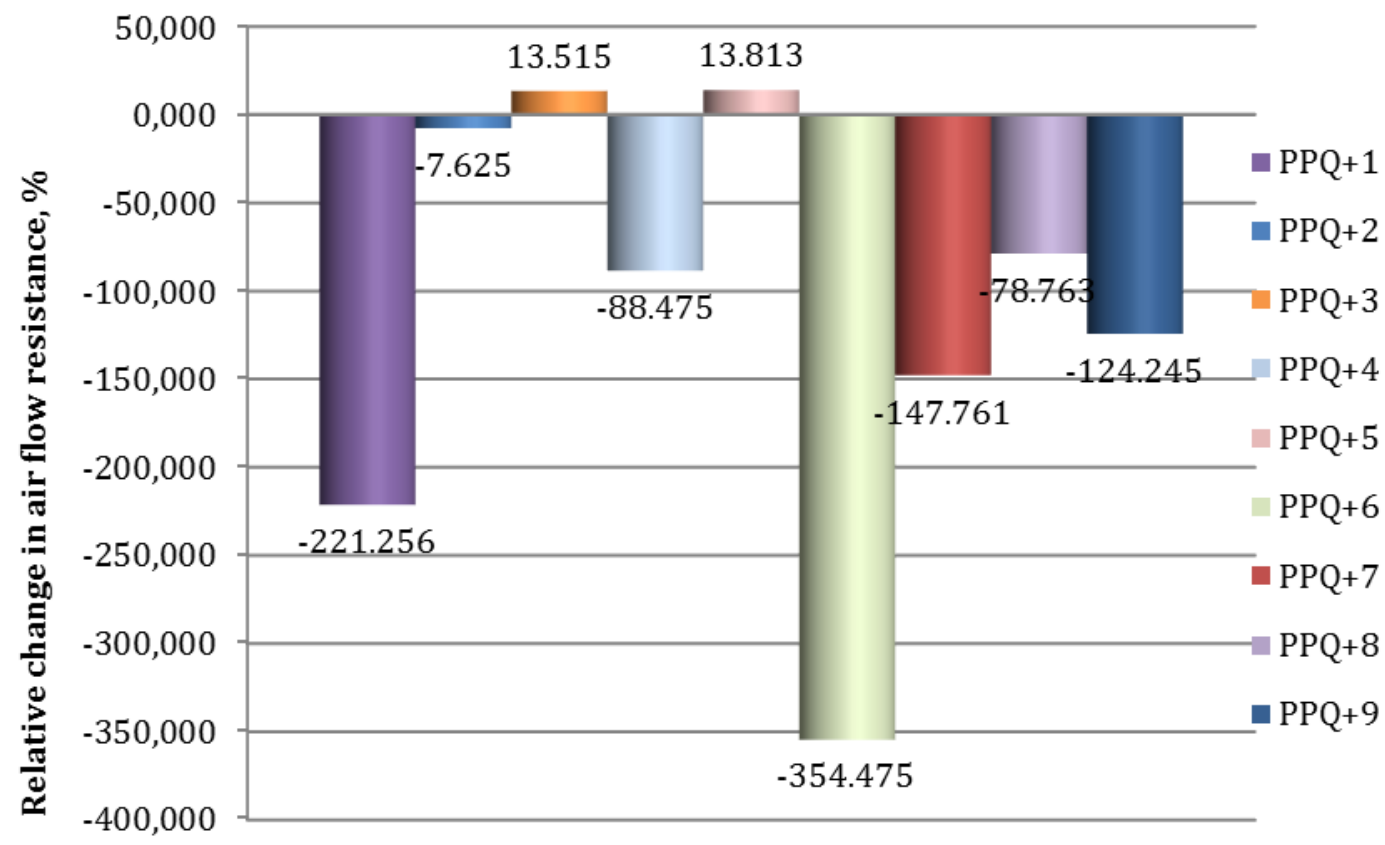

Figure 4. Relative changes in airflow resistance for melt-blown filtration nonwovens containing zeolites or MCM-41 
rose only marginally, reaching $308 \mathrm{~Pa}$, while in the remaining cases, it ranged from $511 \mathrm{~Pa}$ to $1,299 \mathrm{~Pa}$. While the two observed relative reductions in airflow resistance were $13.63 \%$ and $13.99 \%$, respectively, the increases ranged from $7.69 \%$ to $220.98 \%$. This parameter was affected by zeolite dust, which filled some of the interfiber voids. Pursuant to the standard EN 149:2001+A1:2009, the airflow resistance of respirators may not exceed $700 \mathrm{~Pa}$ at $95 \mathrm{~L} / \mathrm{min}$; this requirement was met only by nonwovens containing clinoptilolite, $\mathrm{Na}-\mathrm{X}$, sodalite, $\mathrm{Na}-\mathrm{A}$, BioZeo R.01, as well as MCM-41.

Six of the PP nonwovens modified with zeolites or MCM-41 showed increased filtration effectiveness, while three revealed reduced effectiveness. These results are consistent with other reports [10]. For instance, microcrystalline cellulose and microbiological chitosan incorporated in melt-blown nonwovens compromised their filtration properties. On the other hand, previous works $[8,9]$ using biological agents and modifiers such as perlite and amber reported a significant improvement in the filtration characteristics of polymer nonwovens. The effects of modifiers on the filtration effectiveness of nonwovens are affected by a number of factors, such as the quantity and size of the modifier particles, particle density and polarity, elementary fiber diameters, as well as the physical, chemical, and morphological parameters of the modifiers. Different modifiers may be used to impart new, functional properties to PP melt-blown nonwoven, depending on the particular requirements of a given industry.

\subsection{Testing the sorption capacity of nonwovens for volatiles}

Sorption results for the various PP nonwovens containing zeolites or MCM-41 exposed to the selected test substances are given in Figures 5-8.

Longer reaction times were observed for the reactions of nonwovens with the vapors of harmful substances. Among all the variants of filtration nonwovens containing modifiers, the longest reaction time with toluene vapor at $2 \mathrm{ppm}$ was shown

\section{TOLUENE $50 \mathrm{ppm}$}

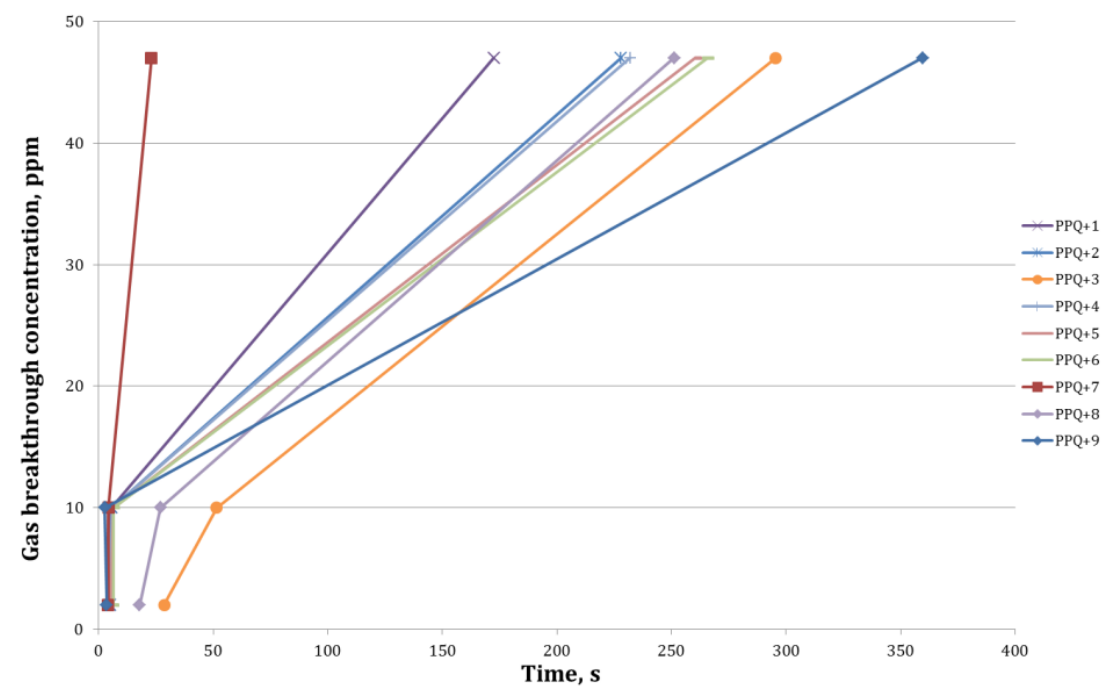

Figure 5. Reaction times of polypropylene melt-blown nonwovens containing zeolites or MCM- 41 with toluene vapor at a concentration of 50 ppm

\section{ACETONE 235 ppm}

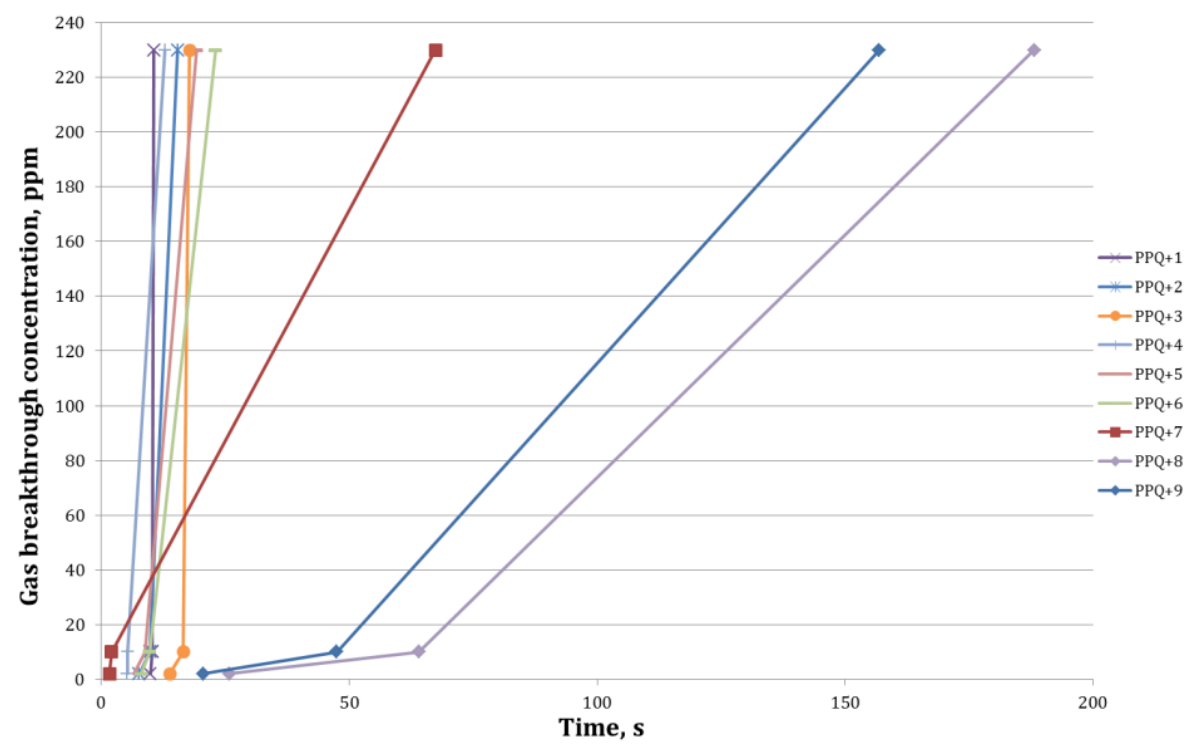

Figure 6. Reaction times of polypropylene melt-blown nonwovens containing zeolites or MCM-41 with acetone vapor at a concentration of $235 \mathrm{ppm}$ 


\section{CYCLOHEXANE 81 ppm}

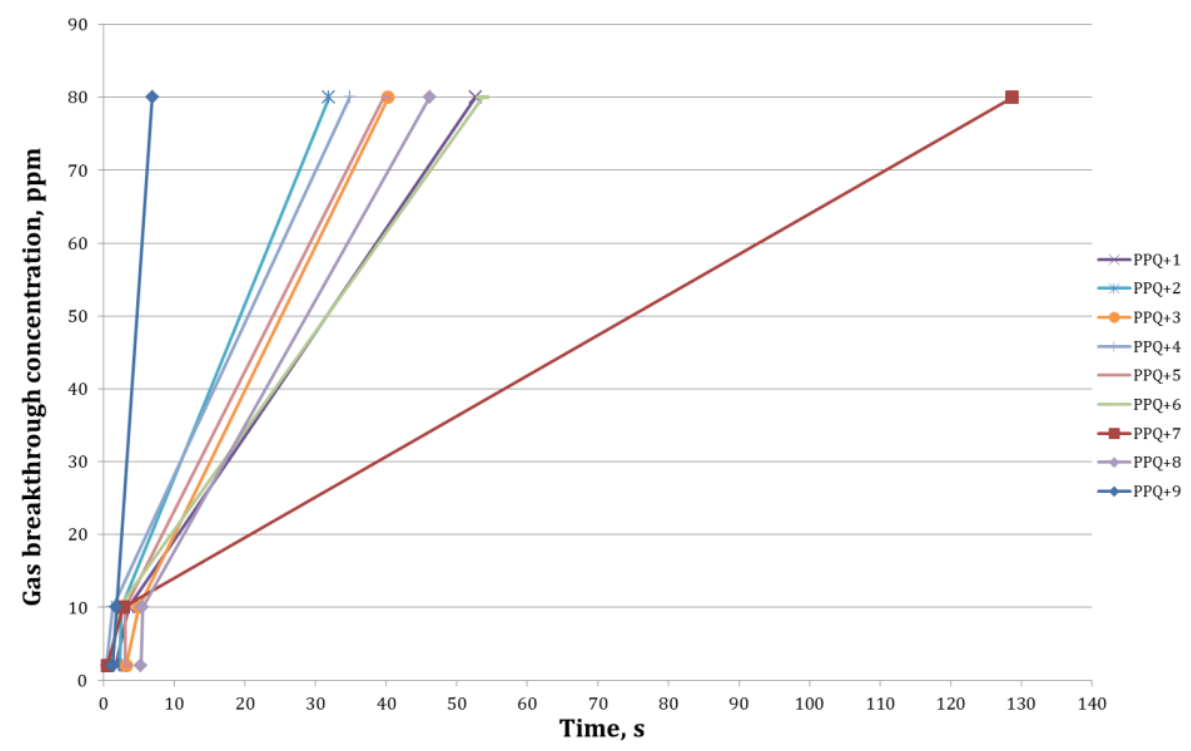

Figure 7. Reaction times of polypropylene melt-blown nonwovens containing zeolites or MCM-41 with cyclohexane vapor at a concentration of $81 \mathrm{ppm}$

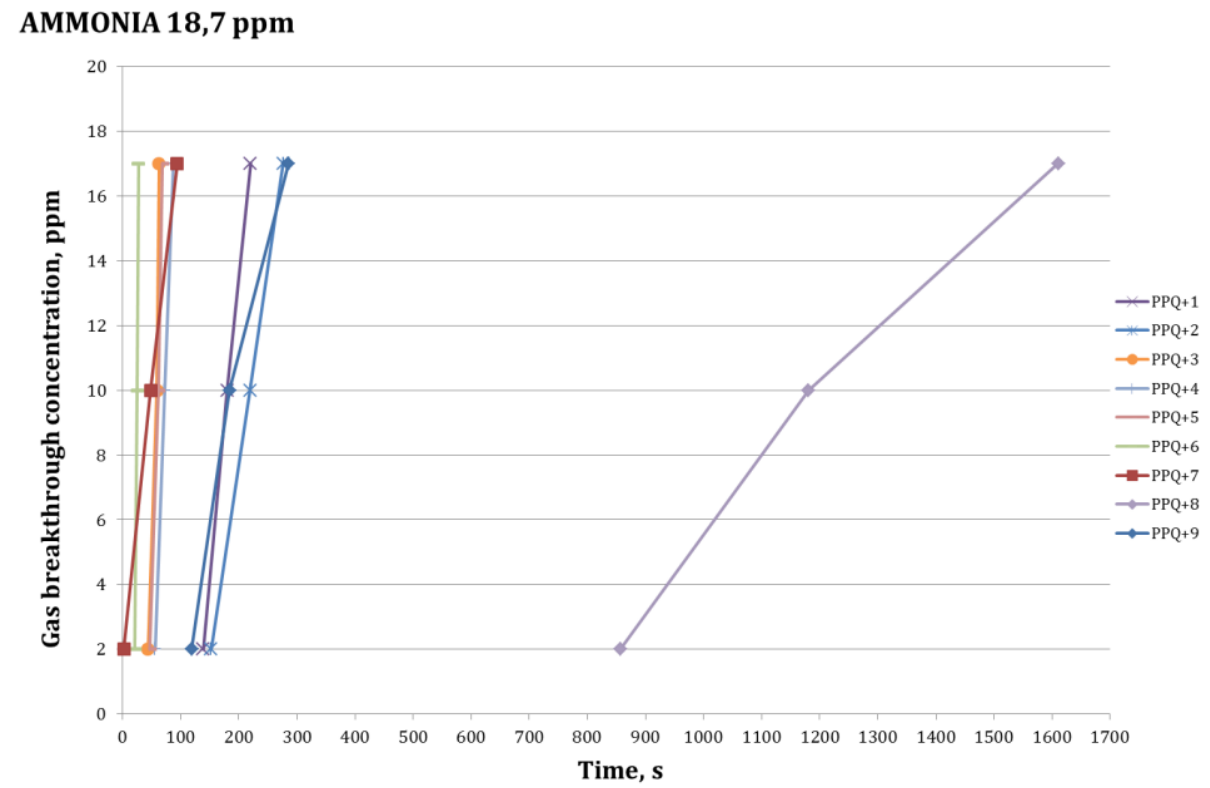

Figure 8. Reaction times of polypropylene melt-blown nonwovens containing zeolites or MCM-41 with ammonia vapor at a concentration of $18.7 \mathrm{ppm}$

by nonwovens with MCM-41 and Na-X zeolite (approximately $30 \mathrm{~s}$ ). The maximum concentration of $50 \mathrm{ppm}$ was obtained after $240-260 \mathrm{~s}$. Although the nonwoven containing BioZeo R.01 zeolite exhibited a concentration of $10 \mathrm{ppm}$ after $2 \mathrm{~s}$, it did not reach the breakthrough concentration until $340 \mathrm{~s}$. In the case of acetone vapor, the nonwoven containing MCM-41 started to react with the test substance after $30 \mathrm{~s}$ at a concentration of $2 \mathrm{ppm}$, with the maximum concentration found after $180 \mathrm{~s}$. The reaction times of PP melt-blown nonwoven containing the studied modifiers to cyclohexane vapor at $10 \mathrm{ppm}$ ranged from $2 \mathrm{~s}$ to $6 \mathrm{~s}$. However, the filter medium containing Na-P1HDTMA zeolite showed the longest reaction time (125 s) at $81 \mathrm{ppm}$. The nonwoven containing MCM-41 showed the best sorption properties toward ammonia vapor after approximately
$810 \mathrm{~s}$ and exhibited reaction with ammonia vapor breakthrough at $2 \mathrm{ppm}$. The maximum concentration of $18.7 \mathrm{ppm}$ was found after $1,600 \mathrm{~s}$ (14 $\mathrm{min})$.

The obtained results were consistent with other studies [29, 31, 37] reporting that zeolites and MCM-41 are good adsorbents of chemical compounds, especially ammonia and toluene vapors. It was found that the higher the concentration of the test substances, the shorter is the breakthrough time.

The presented findings indicate that further research should focus on modifying zeolites with a view to increasing their specific area and achieving the longest possible protection time against volatiles. The tests also show the possibility of 
new applications of zeolites and mesoporous silica materials in nonwovens for respiratory protective equipment.

\section{CONCLUSIONS}

The presented findings show that zeolites and mesoporous silica material MCM-41 can be successfully introduced within the structure of elementary polymer fibers using an environmentally friendly "dry" melt-blown technology with a view to imparting multiple functionalities to nonwovens in one integrated technological process.

The developed method of introducing zeolites and MCM-41 in PP melt-blown nonwovens has enabled the production of multipurpose materials with high protective as well as functional properties. The obtained materials contained the following:

- MCM-41 mesoporous silica material, efficiently preventing the penetration of both liquid and solid particles of harmful aerosols (99.85\% and $99.65 \%$, respectively) at satisfactory airflow resistance and with good capacity for selective adsorption of volatiles, such as acetone and ammonia;

- Na-P1 zeolite modified with HDTMA, efficiently preventing penetration of both liquid and solid particles of harmful aerosols $(99.66 \%$ and $99.70 \%$, respectively) at satisfactory airflow resistance and with good capacity for cyclohexane adsorption.

\section{ACKNOWLEDGMENTS}

The publication is based on the results of Phase IV of the National Program "Improvement of Safety and Working Conditions," financed in the years 2017-2019 in the area of research and development by the Ministry of Science and Higher Education/the National Centre for Research and Development, Warsaw, Poland. The program coordinator is the Central Institute for Labour Protection, National Research Institute, Warsaw, Poland.

\section{References}

[1] Krajewska, B., Kośmider, J. (2005). Standards of air quality. Ochr Powietrza i Probl Odpadów, 6, 181-91.

[2] Makles, Z., Galwas-Zakrzewska, M. (2005). Odorous gases in the work environment. Occupational Safety Science and Practice, 9, 12-16.

[3] Szynkowska, M., Wojciechowska, E., Węglińska, A., Paryjczak, T. (2009). Odors. The current problem in environmental protection. Przemysl Chemiczny, 88(6), 712-720.

[4] Twarowska-Schmidt, K. (2004). Evaluation of the suitability of some biodegradable polymers for the forming of fibres. Fibres \& Textiles in Eastern Europe, 2(46), 15-18.

[5] Zohuriaan-Mehr, M. J., Omidian, H., Doroudiani, S., Kabiri, K. (2010). Advances in non-hygienic applications of superabsorbent hydrogel materials. Journal of Materials Science, 45, 5711-5735.
[6] Żenkiewicz, M., Rytlewski, P., Malinowski, R. (2011). Methods and devices used in modifying polymer materials with low-temperature plasma. Polimery, 56(3), 185-195.

[7] Berrigan, M. R., Moore, E. M., et al. (2009). Composite non-woven fibrous webs having continuous particulate phase and methods of making and using the same, WO 2009/088648 A1.

[8] Brochocka, A., Majchrzycka, K. (2009). Technology for the production of bioactive melt-blown filtration materials applied to respiratory protective devices. Fibres and Textiles in Eastern Europe, 5(76), 92-98.

[9] Brochocka, A., Majchrzycka, K., Makowski, K. (2013). Modified melt-blown nonwovens for respiratory protective devices against nanoparticles. Fibres and Textiles in Eastern Europe, 21, 4(100), 106-111.

[10] Czaplicki, A. (2006). New method and equipment for manufacturing new adsorptive materials with active carbon content. Fibers and Textiles in Eastern Europe, 4(58), 7578.

[11] Jackiewicz, A., Podgórski, A., Gradoń, L., Michalski, J. (2013). Nanostructured media to improve the performance of fibrous filters. KONA Powder and Particle Journal, 30, 244-255.

[12] Kałużka, J., Jankowska, E., Pośniak, M., Ławniczak, D. (2010). Testing the efficiency of the simultaneous air cleaning of dust and gases by fibrous filtering and sorptive structures. Fibres \& Textiles in Eastern Europe, 18, 4(81), 77-81.

[13] Leung, W. W.-F., Hung, C.-H., Yuen, P.-T. (2010). Effect of face velocity, nanofiber packing density and thickness of filtration performance of filters with nanofibers coated on a substrate. Separation and Purification Technology, 71, 30-37.

[14] Podgórski, A., Bałazy, A., Gradoń, L. (2006). Application of nanofibers to improve the filtration efficiency of the most penetrating aerosol particles in fibrous filter. Chemical Engineering Science, 61, 6806-6815.

[15] Sojka-Ledakowicz, J., Latwinska, M., Kałużka, J., Kudzin, M. (2013). Polypropylene nonwovens with natural polymers addition for filtration applications, Polimery, 58, 557-561.

[16] Wang, J., Seong, C. K., Pui, D. Y. H. (2008). Investigation of the figure of merit for filters with single nanofiber layer on substrate. Journal of Aerosol Science, 39, 323-334.

[17] Brochocka, A., Orlikowski, W., Majchrzycka, K., Patent PAT.226187, date of decision 2016.12.20, Fiber forming head for the production of modified electret nonwovens, Poland, Urząd Patentowy RP.

[18] Brochocka, A., Orlikowski, W., Majchrzycka, K., Patent PAT.226188, date of decision 2016.12.20, Fiber forming head for the production of modified electret nonwovens, Poland, Urząd Patentowy RP.

[19] Chroma, J., Jaroniec, M., Ustinov, E.A. (2004). Adsorptive characterization of activated carbons with very well developed porosity. Ochrona Srodowiska, 4(26), 3-9.

[20] Franus, W. (2017). The use of synthetic zeolites in environmental engineering. Monograph of the Committee of Environmental Engineering of the Polish Academy of Sciences (Poland).

[21] Stoeckli, F., Centeno, T.A. (2005). On the determination of surface areas in activated carbons. Carbon, 43, 11841190. 
[22] Franus, W. (2012). Application of zeolites made from fly ash to remove impurities from water and sewage. Monograph of the Committee of Environmental Engineering of the Polish Academy of Sciences (Poland).

[23] Muir, B., Bajda, T. (2016). Organically modified zeolites in petroleum compounds spill cleanup - Production, efficiency, utilization. Fuel Processing Technology, 149, 153-162.

[24] Wolowiec, M., Muir, B., Zieba, K., Bajda, T., Kowalik, M., Franus, W. (2017). Experimental study on the removal of VOCs and PAHs by zeolites and surfactant-modified zeolites. Energy \& Fuels, 31(8), 8803-8812.

[25] Bandura, L., Panek, R., Rotko, M., Franus, W. (2016). Synthetic zeolites from fly ash for an effective trapping of BTX in gas stream. Microporous \& Mesoporous Materials, 223, 1-9.

[26] Derkowski, A., Franus, W., Beran, E., Czimerova, A. (2006). Properties and potential applications of zeolitic materials produced from fly ash using simple methods of synthesis. Powder Technology, 166(1), 47-54.

[27] Bandura, L., Franus, M., Panek, R., Woszuk, A., Franus, $W$. (2015). Characterization of zeolites and their use as adsorbents of petroleum derivatives. Przemysl Chemiczny, 94(3), 323-327.

[28] Bandura, L., Woszuk, A., Kołodyńska, D, Franus, W. (2017). Application of mineral adsorbents for removal of petroleum substances: a review. Minerals, 7, 37.

[29] Wu, Q., Zheng, Y., Jian, J., Wang, J. (2017). Gas sensing performance of ion-exchanged $Y$ zeolites as an impedimetric ammonia sensor. Ionics, 23, 751-758.
[30] Parast, Z. V., Asilian, H., Jafari, A. J. (2014). Adsorption of xylene from air by natural Iranian zeolite. Health Scope, 3(3), e17528.

[31] Gregis, G., Schaefer, S., Sanchez, J. B., Fierro, V., Berger, F., Bezverkhy, I., Weber, G., Bellat, J. P., Celzard, A. (2017). Characterization of materials toward toluene traces detection for air quality monitoring and lung cancer diagnosis. Materials Chemistry and Physics, 192, 374382.

[32] EN 13274-3: 2008 Respiratory protective devices. Methods of tests. Determination of breathing resistance.

[33] EN 13274-7: 2008 Respiratory protective devices. Methods of tests. Determination of particle filter penetration.

[34] EN 14387: 2004+AC:2004 Respiratory protective devices. Gas filter(s) and combined filter(s). Requirements, testing, marking.

[35] EN 149:2001 +A1:2009 - Respiratory protective devices - particle filtering half masks - requirements, testing, marking.

[36] Journal of Laws of the Republic of Poland Warsaw, 23/06/2014, Regulation of the Minister of Labor and Social Policy dated 06.06.2014 on the highest permissible concentrations and intensities of harmful factors for healthy in the work environment.

[37] Opaliński, S., Korczyński, M., Szołtysik, M., Dobrzański, Z., Kołacz, R. (2015). Application of aluminosilicates for mitigation of ammonia and volatile organic compound emissions from poultry manure. Open Chemistry, 13(1), 967-973. 